SEP 91998 . WNGINEERING DATA TRANSMITTAL

\section{To: (Receiving Organization) \\ Distribution}

5. Proj./Prog./Dept./Div.:

HANDI 2000 INTEGRATTON

8. Originator Remarks:

FOR RELEASE

11. Receiver Remarks:

\section{From: (Originating Organization) \\ SYSTEMS FDH}

6. Design Authority/Design Agent/Cog. Engr.:

DAWN E. ADAMS
4. Related EDT No::

$\mathrm{N} / \mathrm{A}$

7. Purchase Order No.:

$\mathrm{N} / \mathrm{A}$

9. Equip./Component No:

N $/$ A

10. System/B/dg./Facility:

$\mathrm{N} / \mathrm{A}$

12. Major Assm. Dwg. No.:

$\mathrm{N} / \mathrm{A}$

13. Permit/Permit Application No.:

$\mathrm{N} / \mathrm{A}$

14. Required Response Date:

$\mathrm{N} / \mathrm{A}$

15 DATA TRANSMITTED

(A)

(A)
Item
No.

(B) Document'Drawing No.$$
\text { . }
$$

\begin{tabular}{l|l}
\hline 1 & HNF - 2961 \\
\hline
\end{tabular}

\begin{tabular}{c|c|c}
$\begin{array}{c}\text { (C) Sheet } \\
\text { No. }\end{array}$ & (D) Rev. \\
No. & (E) Title or Description of Data Transmitted
\end{tabular}

(F)

(F)

(G)

Approval

Desig- Reason

nator ${ }^{\text {mittal }}$

\begin{tabular}{|c|c|c|}
\hline$(\mathrm{H})$ & $(\mathrm{l})$ \\
\hline 1 & $\begin{array}{c}\text { Origi- } \\
\text { nator } \\
\text { Dispo- } \\
\text { stion }\end{array}$ & $\begin{array}{c}\text { Receiv- } \\
\mathrm{er} \\
\text { Dispo- } \\
\text { sition }\end{array}$ \\
\hline & \\
\hline & \\
\hline
\end{tabular}

16.

\begin{tabular}{l|l|l|l}
\hline N/A & REV O & LEGACY SYSTEM RETIREMENT \\
\hline & & PIANT FOR HANDI 2000
\end{tabular}

PLAN FOR HANDI 2000

BUSTNESS MANAGEMENT SYSTEM

KEY
Reason for Transmittal (G)

4. Review

5. Post-Review

6. Dist. (Receipt Acknow. Required)
Disposition $(\mathrm{H}) \&(\mathrm{l})$

\section{Approved}

2. Approved w/comment

3. Disapproved w/comment
4. Reviewed no/comment

5. Reviewed w/comment

6. Receipt acknowledged

SIGNATURE/DISTRIBUTION

(See Approval Designator for required signatures)

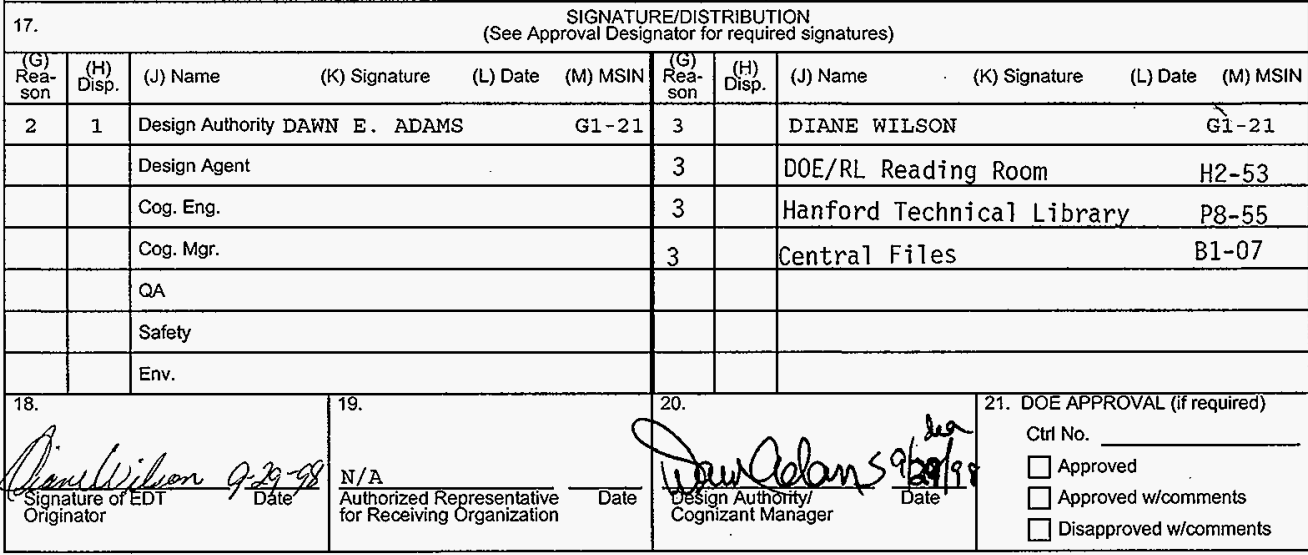




\title{
LEGACY SYSTEM RETIREMENT PLAN FOR HANDI 2000 BUSINESS MANAGEMENT SYSTEM
}

\author{
Dawn E. Adams, FDH \\ 2355 Stevens MSN G1-21 \\ Richland, WA 99352 \\ U.S. Department of Energy Contract DE-AC06-96RL13200

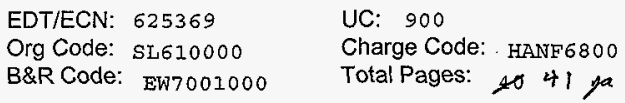

Key Words: HANDI 2000, BUSINESS MANAGEMENT, LEGACY SYSTEM RETIREMENT PLAN BMS, H2K, Y2K, CONVERSION, FINANCIAL DATA SYSTEM, PROJECT ANALYSIS \& REPORTING, ECS, PIDS, PAMM-SCA, PAMM-PRA, WIMS, HIP, EVE, GIC, GSH,WHR

Abstract: Implementation of the Business Management system will replace a number of systems currently in use at Hanford. These systems will be retired when the replacement is complete and the data from the old systems adequately stored and/or converted to the new system. The replacement is due to a number of factors: 1. Year 2000 conversion:... 2. Many redundant custom-made systems:...3. Shift inefficient/complex work processes to commercial standards:...

TRADEMARK DISCLAIMER. Reference herein to any specific commercial product, process, or service by trade name, trademark, manufacturer, or. otherwise, does not necessarily constitute or imply its endorsement, recommendation, or favoring by the United States Government or any agency thereof or its contractors or subcontractors.

Printed in the United States of America. To obtain copies of this document, contact: Document Control Services, P.O. Box 950, Mailstop H6-08, Richland WA 99352, Phone (509) 372-2420; Fax (509) 376-4989.
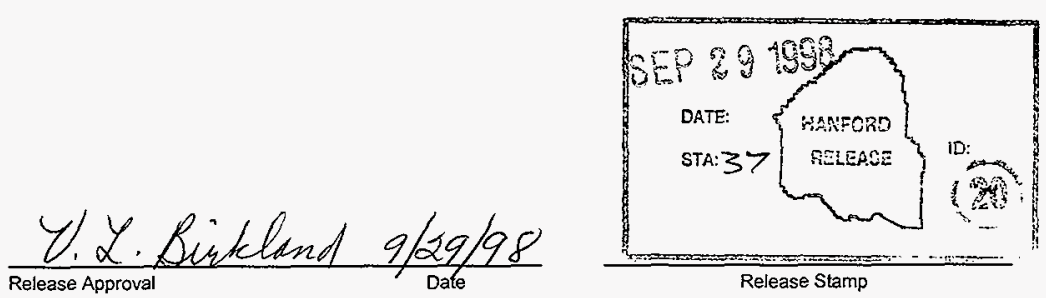

\section{Approved For Public Release}




\title{
Legacy System \\ Retirement Plan
}

\author{
FOR \\ HANDI 2000 \\ BUSINESS MANAGEMENT SYSTEM
}

Prepared by: Tim LeGore, LMSI Software Engineer

Prepared for: Fluor Daniel Hanford

Approved by:

Ratutos. satio

Robert E. Gates, H2K Project Director

Steve Maniey, FDH/CIO Manager

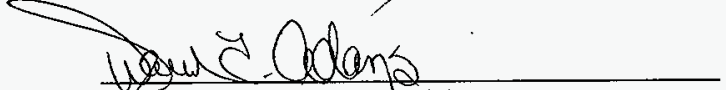

Dawn E. Adams, BMS Project Manager

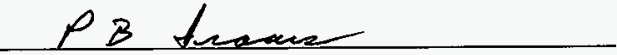

Phillip B. (Brian) Isaacs, LMSI Project Manager $\frac{9 / 29 / 98}{\text { Date }}$

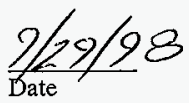

$\frac{9117}{\text { Date }}+98$

$\frac{a / 17 / 98}{\text { Date }}$ 


\section{TABLE OF CONTENTS}

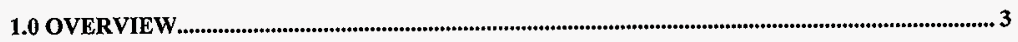

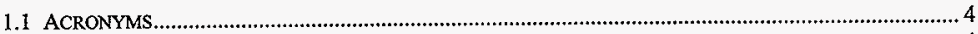

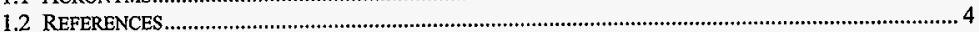

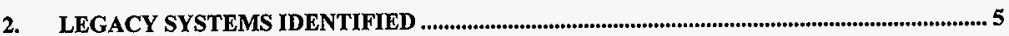

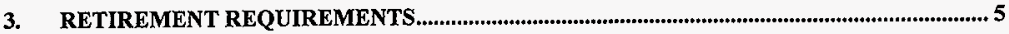

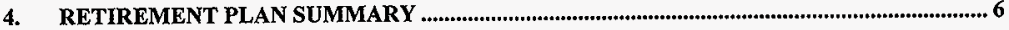

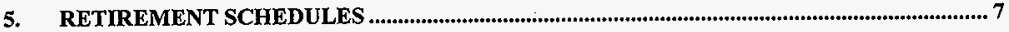

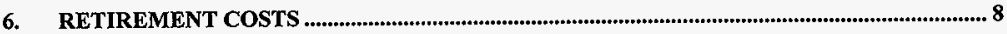

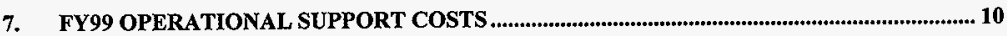

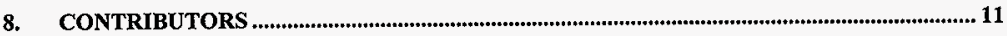

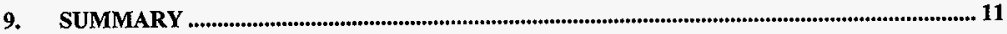

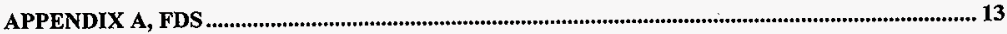

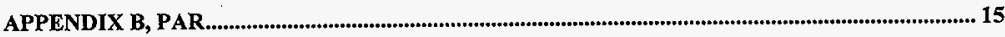

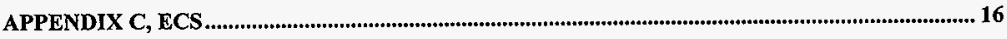

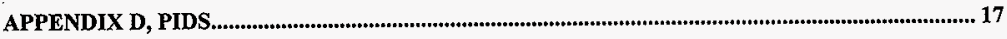

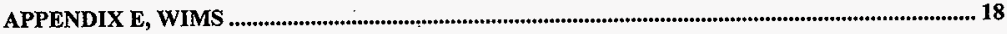

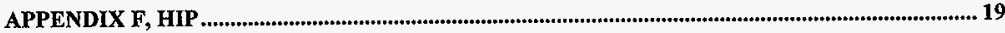

APPENDIX G, PAMM -SCA, -PRA, -APM

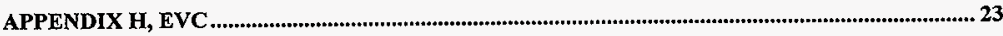

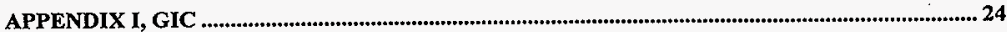

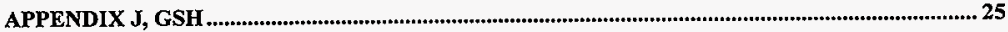

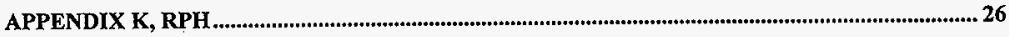

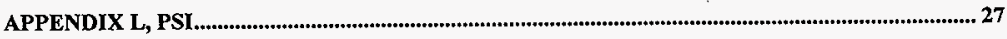

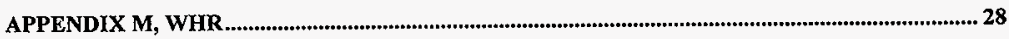

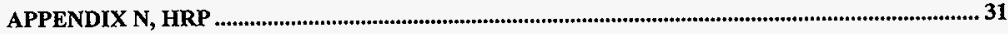

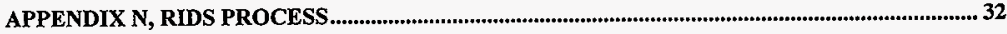




\subsection{Overview}

The implementation of the Business Management System (BMS) will replace a number of systems currently in use at Hanford. These systems will be retired when the replacement is complete and the data from the old systems adequately stored and/or converted to the new system. The replacement is due to a number of factors:

1. Year 2000 conversion: Most of the systems being retired are not year 2000 compliant. Estimates on making these systems compliant approach the costs of replacing with the enterprise system.

2. Many redundant custom-made systems: Maintenance costs on the aging custom developed systems is high. The systems also have overlapping functionality. Replacement with an enterprise system is expected to lower the maintenance costs.

3. Shift inefficient/complex work processes to commercial standards: Many business practices have been developed in isolation from competitive pressures and without a good business foundation. Replacement of the systems allows an opportunity to upgrade the business practices to conform to a market driven approach.

4. Questionable legacy data: Significant amount of data contained within the legacy systems is of questionable origin and value. Replacement of the systems allows for a new beginning with a clean slate and stronger data validation rules

5. Obsolete legacy technology. A number of the systems being retired depend on hardware and software technologies that are no longer adequately supported in the market place.

The IRM Application Software System Life Cycle Standards, HNF-PRO-2778, and the Data Systems Review Board (DSRB) define a system retirement process which involves the removal of an existing system from active support or use either by:

- ceasing its operation or support, or

- replacing it with a new system or

- replacing it with an upgraded version of the existing system.

It is important to note, that activities associated with the recovery of the system, once archived, relates to the ability for authorized personnel to gain access to the data and documentation baseline rather than to ensure the ability to reestablish an operational production system.

The remainder of this document describes the planning for the removal of the identified systems from service at Hanford. The retirement requirements, planning schedules and costs are covered in the body of the document. 
For each system, there is a specific checklist of retirement activities to be followed for performing the retirement. These are included as self-contained appendices. The appendices are intended to serve as the basis for developing Statements of Work from Fluor Daniel Hanford (FDH) to LMSI when FDH determines that each of the systems has been effectively replaced and retirement activities can be initiated.

\subsection{Acronyms}

$\begin{array}{ll}\text { BMS } & \text { Business Management System } \\ \text { COTS } & \text { Commercial Off The Shelf software } \\ \text { ECS } & \text { Expense Commitment System } \\ \text { ESOE } & \text { End System Operating Environment } \\ \text { EVC } & \text { Electronic Vendor Catalogue } \\ \text { FDH } & \text { Fluor Daniel Hanford } \\ \text { FDS } & \text { Financial Data System } \\ \text { GIC } & \text { General Inventory Catalogue } \\ \text { GSH } & \text { General Supplies Inventory } \\ \text { HIP } & \text { Hanford Inventory Program } \\ \text { HRP } & \text { Human Resources Payroll } \\ \text { IRS } & \text { Internal Revenue Service } \\ \text { LMSI } & \text { Lockheed Martin Services, Inc. } \\ \text { NARA } & \text { National Archives and Records Administration } \\ \text { OSSP } & \text { Organizational Standard Software Process } \\ \text { PAMM-APM Procurement And Material Management - Accounts Payable Module } \\ \text { PAMM-PRA Procurement And Material Management - Payment Requestor } \\ & \text { Administration } \\ \text { PAMM-SCA } & \text { Procurement And Material Management - System Contract } \\ & \text { Administration } \\ \text { PAR } & \text { Project Analysis and Reporting } \\ \text { PIDS } & \text { Purchasing Information Document System } \\ \text { RHA } & \text { Records Holding Area } \\ \text { RIDS } & \text { Records Identification and Disposition Schedule } \\ \text { RMIS } & \text { Records Management Information System } \\ \text { RPH } & \text { Rockwell Purchasing History } \\ \text { SMS } & \text { Site Management System } \\ \text { TBD } & \text { To Be Determined } \\ \text { WHR } & \text { Westinghouse Human Resources } \\ \text { WIMS } & \text { Warehouse Inventory Management System } \\ & \end{array}$

\subsection{References}

N/A 


\section{Legacy Systems Identified}

Direction to retire the systems identified must come from the System Owner. This retirement planning is being performed in anticipation of the specific direction to retire these systems.

The candidate systems to be retired are:

Table 1: Candidate Systems for HANDI 2000 Retirement

\begin{tabular}{|l|l|}
\hline FDS & Financial Data System \\
\hline PAR & Project Analysis and Reporting \\
\hline ECS & Expense Commitment System \\
\hline PIDS & Purchasing Information Document System \\
\hline PAMM-SCA & Systems Contract Administration \\
\hline PAMM-APM & Accounts Payable Module \\
\hline PAMM-PRA & Payment Requestor Administration \\
\hline WIMS & Warehouse Inventory Management System \\
\hline HIP & Hanford Inventory Program \\
\hline EVC & Electronic Vendor Catalogue \\
\hline GIC & General Inventory Catalogue \\
\hline GSH & General Supplies Inventory \\
\hline RPH & Rockwell Purchasing History \\
\hline WHR & Westinghouse Human Resources \\
\hline HRP & Human Resources Payroll \\
\hline
\end{tabular}

Property Sampling Inventory (PSI) was originally included in this planning process but has since been withdrawn from the list. It is to be interfaced with the new BMS system.

EVC is not a system per se', but a process for manually transferring \& formatting data for emplacement in soft reporting. In effect the system is already retired and no longer exists.

\section{Retirement Requirements}

The process defined by the DSRB identifies 2 basic end states:

- Retirement of the data only, includes archiving the data per requirements and taking the hardware off line. 
- Standard System Retirement includes archiving the data per requirements, system/project documentation (i.e. System Specification, System Design Document, Project File, etc.), and the software (source code, tables, dictionaries, etc.).

\section{Retirement Plan Summary}

The general strategy is for Standard System Retirement. The data to be retained will be identified via the Record Identification and Disposition Schedule (RIDS) forms. Only record material that is not being converted to the BMS will be retained after the retirement. The length of the retention wili be as specified on the RIDS form.

Hardcopy documentation will be preserved in the Records Holding Facility. Electronic Documentation and records that may need to be accessed will be retained in either the Records Management Information System (RMIS) or in the 339A Tape Library. References to tapes in the appendices are to be understood to include all versions of the tape. Other documentation and records will be sent to the Records Holding Area as specified in the RIDS.

Any hardware that is dedicated to a retired system will be released for reuse.

The exceptions to this strategy are FDS, PIDS and PAMM. Due to

- The complex nature of the data,

- A perceived future need to access the data,

- The volume of data NOT being converted to the BMS,

- Limited resources for converting the data and/or setting up data repositories in other systems,

These three systems will be placed in a 'stand down' mode in which limited access to the data for ad hoc reporting is retained. Production operation will be closed out (see Appendix A, D and $\mathrm{G}$ for details). Complete retirement will be addressed in Fiscal Year 1999 (FY99), as resources become available. 


\section{Retirement Schedules}

The approximate time frame for retirement activities to take place are shown in table 2:

Table 2: System Retirement Time Frames

\begin{tabular}{|l|l|}
\hline System & Time Frame \\
\hline \hline FDS & TBD \\
\hline PAR & February 26,1999 \\
\hline ECS & February 26, 1999 \\
\hline PDS & December 31, 1999 \\
\hline PAMM-SCA & December 31, 1999 \\
\hline PAMM-APM & December 31, 1999 \\
\hline PAMM-PRA & December 31, 1999 \\
\hline WIMS & February 26, 1999 \\
\hline HIP & February 26, 1999 \\
\hline EVC & N/A \\
\hline GIC & February 26,1999 \\
\hline GSH & February 26,1999 \\
\hline RPH & February 26,1999 \\
\hline WHR & February 26,1999 \\
\hline HRP & February 26,1999 \\
\hline
\end{tabular}

Complete retirement for FDS, PIDS and PAMM must await decisions as to a final data repository and construction of the repository. 


\section{Retirement Costs}

Table 3 summarizes the estimated hours to perform the retirement actions described in the appendices.

Table 3: System Retirement Labor

\begin{tabular}{|l|r|r|r|}
\hline System & $\begin{array}{r}\text { LMSI labor } \\
\text { (Manhours) }\end{array}$ & $\begin{array}{r}\text { FDH Labor } \\
\text { (Manhours) }\end{array}$ & $\begin{array}{r}\text { Total } \\
\text { (Manhours) }\end{array}$ \\
\hline FDS & 40 & 8 & 48 \\
\hline PAR & 24 & 0 & 24 \\
\hline ECS & 20 & 4 & 24 \\
\hline PIDS & 0 & 0 & 0 \\
\hline WIMS & 40 & 8 & 48 \\
\hline HIP & 20 & 4 & 24 \\
\hline PAMM -SCA & 40 & 8 & 48 \\
-PRA, -APM & & & \\
\hline EVC & 0 & 0 & 0 \\
\hline GIC & 8 & 0 & 8 \\
\hline GSH & 8 & 0 & 8 \\
\hline RPH & 116 & 10 & 126 \\
\hline WHR \& HIP & 20 & 8 & 28 \\
\hline \hline TOTALS & 336 & 50 & 386 \\
\hline
\end{tabular}


Table 4 summarizes the anticipated costs for recovering the data into a database for possible use at a later time. NOTE: These costs do NOT cover analysis of the data OR the redevelopment of data analysis capability. These estimates only cover retrieval of the data into a database, i.e., re-establishing read / write capability. Costs for systems in "stand down" mode are not estimated as data recovery is not required at this time.

Table 4: Data recovery labor

\begin{tabular}{|l|c|c|c|}
\hline System & $\begin{array}{l}\text { LMSI labor } \\
\text { (Manhours) }\end{array}$ & $\begin{array}{l}\text { FDH Labor } \\
\text { (Manhours) }\end{array}$ & $\begin{array}{l}\text { Total } \\
\text { (Manhours) }\end{array}$ \\
\hline \hline FDS & 0 & 0 & 0 \\
\hline PAR & 0 & 0 & 0 \\
\hline ECS & 0 & 0 & 0 \\
\hline PIDS & 0 & 0 & 0 \\
\hline WIMS & 0 & 0 & 0 \\
\hline HIP & 0 & 0 & 0 \\
\hline $\begin{array}{l}\text { PAMM -SCA } \\
\text {-PRA, -APM }\end{array}$ & 0 & 0 & 0 \\
\hline EVC & 0 & 0 & 0 \\
\hline GIC & 0 & 0 & 0 \\
\hline GSH & 0 & 0 & 0 \\
\hline RPH & 40 & 8 & 48 \\
\hline WHR \& HRP & 40 & 8 & 48 \\
\hline TOTALS & 80 & 16 & 96 \\
\hline
\end{tabular}

Note: Engineering Estimate only 


\section{FY99 Operational Support Costs}

A number of systems will require a nominal level of support to maintain the "stand down" condition and ad hoc reporting capabilities desired by FDH. The estimated support levels are shown in table 5

Table 5: Estimated FY99 Support Levels

\begin{tabular}{|c|c|c|c|}
\hline System & $\begin{array}{l}\text { LMSI } \\
\text { Support }\end{array}$ & $\begin{array}{l}\text { FDH } \\
\text { Support }\end{array}$ & $\begin{array}{l}\text { License \& } \\
\text { maintenance Fees }\end{array}$ \\
\hline$\overline{F \overline{D S}}$ & (intiminours & (minamfours) & (forlars) \\
\hline PAR & $\overline{0}$ & 0 & $\$ 0$ \\
\hline $\mathrm{ECS}$ & 0 & 0 & $\$ 0$ \\
\hline PIDS & 200 & 0 & \\
\hline WIMS & 0 & 0 & $\$ 0$ \\
\hline HIP & 0 & 0 & $\$ 0$ \\
\hline $\begin{array}{l}\text { PAMM -SCA, } \\
\text {-PRA, -APM }\end{array}$ & 3000 & 500 & $\$ 22,000$ \\
\hline EVC & 0 & 0 & $\$ 0$ \\
\hline $\mathrm{GIC}$ & $\overline{0}$ & 0 & $\$ 0$ \\
\hline$\overline{\mathrm{GSH}}$ & 0 & 0 & $\$ 0$ \\
\hline $\mathrm{RPH}$ & 0 & 0 & So \\
\hline WHR \& HRP & 200 & 0 & $\$ 0$ \\
\hline TOTALS & 3600 & 500 & $\$ 22,000$ \\
\hline
\end{tabular}

Note: Engineering Estimate only 


\section{Contributors}

Contributors to this retirement plan are shown in table 6 .

Table 6: Retirement Plan Contributors

\begin{tabular}{|l|l|l|l|}
\hline System & System Analyst LMSI & Technical Owner FDH & Business Owner FDH \\
\hline \hline FDS & Ron Fryer & Don Layfield & Kevin Adamson \\
\hline PAR & Rich Blake & Richard Marshall & Richard Marshall \\
\hline ECS & Ron Fryer & Paul Felts/Chris Hopkins & Kevin Adamson \\
\hline PIDS & Errol Story & Kim Schultz & Pat Marmo \\
\hline WIMS & Dennis Johnson & Paulette White (DYN) & Paulette White (DYN) \\
\hline HIP & Dennis Johnson & Paulette White (DYN) & Paulette White (DYN) \\
\hline PAMM-SCA \\
-PRA, -APM & Bob Ellis / Dave Langford & Debbie Long/ Bob Allen & Pat Marmo/ Paul Felts \\
\hline EVC & Dennis Johnson & NA & NA \\
\hline GC & Dennis Johnson & Paulette White(DYN) & Paulette White (DYN) \\
\hline GSH & Dennis Johnson & Paulette White (DYN) & Paulette White (DYN) \\
\hline RPH & Frederick (Scott) Brim & Michael L Taylor & Patrick Marmo \\
\hline WHR \& HRP & Mark Freeman & Leroy Kelsch & Mike Byrd Todd Byers \\
\hline PSI & NA & Verna Bonefield & NA \\
\hline
\end{tabular}

\section{Summary}

The legacy system retirement effort for FY99 is summarized in table 7:

Table 7: Legacy System Retirement Summaary

\begin{tabular}{|l|r|r|r|rr|}
\hline Effort type & \multicolumn{1}{|l|}{ LMSI } & FOH & Total & \multicolumn{2}{|l|}{ expense fundi } \\
\hline \hline Retirement & 336 & 50 & 386 & $\$$ & - \\
\hline Data Recovery (Continge & 80 & 16 & 96 & $\$$ & - \\
\hline Operational support & 3600 & 500 & 4100 & $\$$ & 22,000 \\
\hline \hline Totals & 4016 & 566 & 4582 & $\$$ & 22,000 \\
\hline
\end{tabular}

Note: Engineering Estimate only 
$\therefore, \therefore$

\section{APPENDICES}




\section{APPENDIX A, FDS}

\section{Financial Data System}

At this time, there is some remaining ambiguity about the future use of data currently resident in FDS and stored in the tape library. There appears to be a long term need for limited access to the data for multi year project analysis and trending as well as Internal Revenue Service (IRS) audit and data retrieval. Since this data is not being converted to the BMS, then the capability to retrieve and analyze the data is required. At this time, resources are limited in providing another means of data access. The recommendation at this time is to place FDS in a "stand down" condition with the following characteristics:

1. No new data will be fed FDS after the FY98 year-end closing process is finished.

2. All production triggers will be removed, i.e., FDS will no longer automatically process data.

3. All FDS automatic reports and data feeds will be suspended

4. The accumulated data on tape, through FY98 will remain available in the 339A tape library.

5. Access to the FDS for ad hoc data retrieval and processing will be limited to approximately 6 Expert Analysts in FDH and a minimal (number TBD) LMSI FDS support team

Complete retirement of FDS must await decisions regarding the ultimate long-term storage of the data and resource availability.

Since FDS is projected to still be in stand down mode after $3-31-99$, Y2K contingency planning must be completed for FDS.

The Completed Retirement Checklist is:

1. Hardware Redeployment: None

2. Network Administration Coordination: Coordination is required to use the Site Management System software (SMS) to locate all General User client side software and remove from client machines.

3. Production Schedule Updates: Production schedules will be updated after final production cycle to roll data to Soft Reporting and long-term storage. Emergency Call lists will be updated. New schedules and call lists will reflect the fact that FDS will receive no new input and produce no regular reports.

4. Jet Form Removal: N/A

5. User Access Removal: General User Access will be denied from the administrator's end when the year end processing is complete and summary data has been made available through Soft Reporting.

6. Data Retention: Data retention requirements are specified on the RIDS form. 
7. Software Distribution Removal: N/A

8. Documentation Storage: All official documentation for the system is in electronic formats. Documentation, source code and scripts will be sent to Records Management Information System (RMIS) as will a master index file of the material.

9. Termination of License Agreements: N/A.

10. Delete/Archive mailbox data: N/A

11. RIDS / QA updates: Updated as a result of this planning

12. End User De-Installation: Via SMS, see \#2 


\section{APPENDIX B, PAR}

\section{Performance Analysis and Reporting}

The Completed Retirement Checklist is:

1. Hardware Redeployment: Y, a dedicated 486 server (WHC391) will be re-deployed.

2. Network Administration Coordination: $\mathrm{N}$

3. Production Schedule Updates: N, PAR is driven from FDS triggers - Turn off FDS and PAR stops automatically.

4. Jet Form Removal: $\mathrm{N}$

5. User Access Removal: $N$

6. Data Retention: N, PAR does not maintain or own any data.

7. Software Distribution Removal: $N$

8. Documentation Storage: System documentation only. Hardcopy will be sent to RHA, electronic files will be sent to RMIS along with an index file of the documentation.

9. Termination of License Agreements: $\mathrm{N}$

10. Delete/Archive mailbox data: $N$

11. RIDS / QA updates: RIDS form updated as a result of this planning process

12. End User De-Installation: $Y$, removal is optional at the user's discretion. This is a manual process as there is not a standardized desktop installation for SMS to operate on.

Electronic files to be stored in RMIS:

- System Documentation: Users Manual IIWHC391IPARADMINIPARDOC.LJ3

- Source Code: IIWHC391।PARADMIN

- $\mathrm{C}$ and D drive contents of PAR workstation WC26759 (2261 computer room)

Hardcopy documentation to be sent to RHA:

- System Documentation: Project Workbook

- System Documentation: Design Documentation 


\section{APPENDIX C, ECS}

Expense Commitment System

The Completed Retirement Checklist is:

1. Hardware Redeployment: N, ECS operates on the Enterprise server which will be dealt with separately

2. Network Administration Coordination: $N$

3. Production Schedule Updates: Y, production triggers from FDS will be suspended and the call list modified

4. Jet Form Removal: $\mathrm{N}$

5. User Access Removal: $\mathrm{Y}$, user access will be denied after FDS year-end closing is complete.

6. Data Retention: N, ECS does not own or retain any data

7. Software Distribution Removal: $N$

8. Documentation Storage: $Y$, Electronic documentation will be sent to the RMIS.

9. Termination of License Agreements: $N$

10. Delete/Archive mailbox data: $N$

11. RIDS / QA updates: Updated as a result of this planning process.

12. End User De-Installation: $N$

Electronic documentation to be sent to the RMIS:

- System Documentation

- IIAp016IFDSDOCIPRODIECS

- Source Code:

- ECS000.PROD.SRCELIB

- UCCELT.PROD.JCLLIB 


\section{APPENDIX D, PIDS}

Purchasing Information Document System

The recommendation at this time is to place the PIDS in a "stand down" condition with the following characteristics:

1. No new data will be fed to PIDS after the FY98 year-end closing process is finished.

2. All production triggers will be removed, i.e., PIDS will no longer automatically process data.

3. All PIDS automatic reports and data feeds will be suspended. Particularly, archival of data into RPH will be discontinued allowing RPH to be retired prior to PIDS being retired.

4. The accumulated data, through FY1998 will remain available in the 339A tape library.

5. Access to the PIDS for ad hoc data retrieval and processing will be limited to Expert Analysts in FDH and a minimal (number TBD) LMSI PIDS support team

Since PIDS is projected to still be in stand down mode after 3-31-99, Y2K contingency planning must be completed for PIDS.

The Completed Retirement Checklist is:

1. Hardware Redeployment: N, runs on the enterprise server. The E.S. is covered under a separate retirement effort.

2. Network Administration Coordination: $Y$, no current coordination but expect to use SMS to identify client side machines.

3. Production Schedule Updates: Y, Emergency Call lists will be updated.

4. Jet Form Removal: N

5. User Access Removal: Y

6. Data Retention: N, PIDS current data is being passed to BMS. Old PIDS data has already been passed to RPH.

7. Software Distribution Removal: $N$

8. Documentation Storage: $Y$, system documentation only.

9. Termination of License Agreements: $N$

10. Delete/Archive mailbox data: $N$

11. RIDS / QA updates: $N$

12. End User De-Installation: $Y$ 


\section{APPENDIX E, WIMS}

Warehouse Inventory Management System

The Completed Retirement Checklist is:

1. Hardware Redeployment: Reassign the Sun workstation to Judy Springer's group.

2. Network Administration Coordination: Use SMS to locate and identify all networked machines containing a WIMS Icon and associated script/software

3. Production Schedule Updates: Remove WIMS from the production schedule and update the emergency call lists.

4. Jet Form Removal; N/A

5. User Access Removal: User Access will be denied from the administrator's end when the year end processing is complete.

6. Data Retention: Necessary and sufficient data is being converted from WIMS to the new BMS. After conversion and startup of the BMS on 10-1-98, no data retention from WIMS is required.

7. Software Distribution Removal: The application will be removed from Software Distribution after User access is denied.

8. Documentation Storage: Electronic documentation and source code will be sent to RMIS along with an index file. Send hardcopy documentation to the Records Holding Area.

9. Termination of License Agreements: Contracts will be directed to terminate the license agreement with DynaCom after WIMS access is denied.

10. Delete/Archive mailbox data: N/A

11. RIDS / QA updates: updated as a result of this planning

12. End User De-Installation: After User Access is denied and WIMS removed from software distribution, then SMS will be used to remove client side software from the user machines.

Documentation to be sent to RMIS:

- System Documentation:

- C:Iwpdatalwim

- Source Code:

- UCCELT.PROD.LOADLIB.WIM

- WIM000.DEVL.SRCELIB.WIM

- UCCELT.PROD.JCLLIB.WIM 


\title{
APPENDIX F, HIP
}

\author{
Hanford Inventory Program
}

The Completed Retirement Checklist is:

1. Hardware Redeployment: 1 dedicated File Server and a work station will be available for redeployment:

- WHC101: WC40823 is a 486 based server and the primary server for HIP

- WHC102: WC42384 is a 486 based workstation.

There are also components of HIP on the enterprise server and the users PC. The ES will be covered under a separate retirement plan. The user's workstations are not available for redeployment.

2. Network Administration Coordination: Coordination is required to use SMS to locate all client side software (.bat files) and remove from client machines.

3. Production Schedule Updates: Production schedules will be updated after final production cycle. Emergency Call lists will be updated.

4. Jet Form Removal: N/A

5. User Access Removal: User Access will be denied from the administrator's end when the year end processing is complete and summary data made available through Soft Reporting.

6. Data Retention: Necessary and sufficient (but not all) data is being converted from HIP to the new BMS. After conversion and startup of the BMS on 10-1-98, no data retention from HIP is required.

7. Software Distribution Removal: $\mathrm{N}$

8. Documentation Storage: Hardcopy documentation will be sent to RHA. Source code will be sent to RMIS along with an index file of the information.

9. Termination of License Agreements: N?

10. Delete/Archive mailbox data: $N$

11. RIDS / QA updates: updated as a result of this planning effort

12. End User De-Installation: Use SMS to remove Client side software after user access is denied.

Electronic files to be sent to RMIS:

- System Documentation

- IIAP010IPMADMINIHIP

- Source Code:

- UCCELT.PROD.LOADLIB.HIP

- HIP000.PROD.SRCELIB.HIP

- UCCELT.PROD.JCLLIB.HIP

Hardcopy Documentation to be sent to the RHA: 
- System Documentation: System Test Plan

- System Documentation: System Test Package 


\title{
APPENDIX G, PAMM -SCA, -PRA, -APM
}

\author{
PAMM-SCA Systems Contract Administration \\ PAMM-PRA Payment Requestor Administration \\ PAMM-APM Accounts Payable Module
}

There is current need to maintain operation of the PAMM system, specifically the APM module through February, 1999 for tac accounting purposes. After this time limited access will be required to handle data closeout and conversion issues. The recommendation at this time is to place the PAMM system in a "stand down" condition with the following characteristics:

6. No new procurement data will be fed to PAMM after the FY98 year-end closing process is finished.

7. All production triggers will be removed, i.e., PAMM will no longer automatically process data.

8. All PAMM automatic reports and data feeds will be suspended

9. The accumulated data, through FY1998 will remain available in PAMM.

10. Access to the PAMM for ad hoc data retrieval and processing will be limited to 3 Expert Analysts in FDH and a minimal (number TBD) LMSI PAMM support team

Complete retirement of PAMM must await decisions regarding the ultimate long-term storage of the data and resource availability.

Since PAMM is projected to still be in stand down mode after 3-31-99, Y2K contingency planning must be completed for FDS.

The Completed Retirement Checklist is:

1. Hardware Redeployment: Yes. PAMM runs on a dedicated Data General Server that can be released for reassignment after final retirement.

2. Network Administration Coordination: Yes: Deactivation of CTS support and removal of "HUH" information

3. Production Schedule Updates: Yes, Both for the Data general server and to remove Process Triggers from applications on the Enterprise Server. Emergency Call lists will be updated.

4. Jet Form Removal: No

5. User Access Removal: Yes

6. Data Retention: No. PAMM passes essential data to the RPH system for long term storage. Complete the final production run at year-end to assure that all required data is passed to RPH.

7. Software Distribution Removal: Yes 
8. Documentation Storage: Yes. Hardcopy Documentation will be sent to Records Holding. Electronic documentation will be written to RMIS in native file formats. A master index file describing the documentation in RMIS will be prepared and also saved in RMIS

9. Termination of License Agreements: Yes, 10 different software license agreements need to be terminated.

10. Delete/Archive mailbox data: Deletion of the mailbox.

11. RIDS / QA updates: Yes - performed when this plan was prepared.

12. End User De-Installation: Yes, use SMS to delete the icon and supporting code from the user's desktop. 


\section{APPENDIX H, EVC}

Electronic Vendor Catalogue

The Completed Retirement Checklist is:

1. Hardware Redeployment: N/A

2. Network Administration Coordination: N/A

3. Production Schedule Updates: N/A

4. Jet Form Removal: N/A

5. User Access Removal: N/A

6. Data Retention: N/A

7. Software Distribution Removal: N/A

8. Documentation Storage: N/A

9. Termination of License Agreements: N/A

10. Delete/Archive mailbox data: N/A

11. RIDS / QA updates: N/A

12. End User De-Installation: N/A

EVC is not a system per se', but a process for manually transferring \& formatting data for emplacement in soft reporting. There is no source code, documentation or records to be considered. Simply instruct the analyst to cease and desist performing the manual process. 


\section{APPENDIX I, GIC}

General Inventory Catalogue

The Completed Retirement Checklist is:

1. Hardware Redeployment: GIC runs on the Enterprise Server and an ESOE workstation. The ES is covered under a separate retirement plan. The ESOE workstation will not be redeployed.

2. Network Administration Coordination: N/A

3. Production Schedule Updates: Production schedules will be updated after the final production cycle to roll data to Soft Reporting. Emergency Call lists will be updated.

4. Jet Form Removal: N/A

5. User Access Removal: N/A (users do not have direct access. Access to data is through Soft Reporting.

6. Data Retention: 1 year in Soft Reporting. This is automatic, no action required during retirement of the system

7. Software Distribution Removal; N/A

8. Documentation Storage: Send Documentation and Source to RMIS.

9. Termination of License Agreements: N/A

10. Delete/Archive mailbox data: N/A

11. RIDS / QA updates: updated as a result of this planning effort.

12. End User De-Installation: N/A

Documentation to be sent to RMIS:

- System Documentation:

- IIAP010.PMADMINIGIC

- Source Code:

- UCCELT.PROD.LOADLIB.GIC

- GIC000.PROD.SRCELIB.GIC

- UCCELT.PROD.JCLLIB.GIC 


\section{APPENDIX J, GSH}

General Supplies Inventory

The Completed Retirement Checklist is:

1. Hardware Redeployment: GSH runs on the Enterprise Server and an ESOE workstation. The ES is covered under a separate retirement plan. The ESOE workstation will not be redeployed.

2. Network Administration Coordination: N/A

3. Production Schedule Updates: Production schedules will be updated after the final production cycle. Emergency Call lists will be updated.

4. Jet Form Removal: N/A

5. User Access Removal: N/A (users do not have direct access. Access to data is through Soft Reporting.

6. Data Retention: 1 year in Soft Reporting. This is automatic, no action required during retirement of the system

7. Software Distribution Removal; N/A

8. Documentation Storage: Send Hardcopy and Source Code tapes to Records Holding

9. Termination of License Agreements: N/A

10. Delete/Archive mailbox data: N/A

13. RIDS / QA updates: updated as a result of this planning effort

11. End User De-Installation: N/A

Documentation to be sent to RMIS:

- System Documentation

- C:IWPDATAISM-021.DOC

- Source Code:

- UCCELT.PROD.LOADLIB.GSH

- E40778.TEST.SRCELIB.GSH

- UCCELT.PROD.JCLLIB.GSH 


\title{
APPENDIX K, RPH
}

\author{
Rockwell Purchasing History
}

The Completed Retirement Checklist is:

1. Hardware Redeployment: N, The RPH system resides on the Enterprise server which will be retired under a separate plan

2. Network Administration Coordination: $N$

3. Production Schedule Updates, : Yes, Emergency Call list will updated

4. Jet Form Removal: No

5. User Access Removal: $Y$

6. Data Retention: Yes, the last annual production tape written will be preserved and converted to a neutral file format.

7. Software Distribution Removal: No

8. Documentation Storage: Yes, documentation will be boxed and sent to records holding after the system is retired. Source code files will be archived in RMIS.

9. Termination of License Agreements: No

10. Delete/Archive mailbox data: No

11. RIDS / QA updates: See Attachment N

12. End User De-Installation: No.

The data to be retained is identified on the final RIDS form as RPH00OR.PROD.TAPE.RPH*** (Yearly backup of alterations, cost, item, purchase orders, receipt $\&$ archive information). This tape will be recovered, after the year-end closeout and final production run, and processed to convert the data from Nomad specific formats and data structures to comma delimited files. 1 file per table will generated and written to RMIS (optical disk storage) along with a file describing the meta data about the RPH files.

Data recovery for use will require the following process:

- Recover the meta data file from RMIS,

- Construct an ad hoc database in a language of the users choice, e.g. MS Access,

- Recover and load the comma delimited tables, as needed, into the data base

This provides a limited read/write capability for the data. Requirements for future analysis and processing capability have not been established at this time. Estimates for data recovery do NOT include analysis of the data once recovered. 


\section{APPENDIX L, PSI}

Property Sampling Inventory

PSI has been withdrawn from the retirement planning process 


\title{
APPENDIX M, WHR
}

\author{
Westinghouse Human Resources
}

The Completed Retirement Checklist is:

1. Hardware Redeployment: runs on the Enterprise Server which is covered under a separate retirement plan.

2. Network Administration Coordination: $\mathrm{N}$

3. Production Schedule Updates: Yes, Emergency call lists will be updated.

4. Jet Form Removal: some old jetforms from a previous version may exist

5. User Access Removal: Y

6. Data Retention: 3 year history kept on magnetic tape in records holding

7. Software Distribution Removal: $N$

8. Documentation Storage: Hardcopy binders only

9. Termination of License Agreements: N, MSA agreement terminated prior to publication of this plan.

10. Delete/Archive mailbox data: $\mathrm{N}$

11. RIDS / QA updates: Y

12. End User De-Installation: $N$

The data to be Sent to RMIS is identified on the final RIDS form as stored on a series of master tapes:

Year end production tapes, CY1990 through 1997

WHR000N.PROD.YE.PWP010.G0008V00

WHR000N.PROD.YE.PWP010.G0009V00

WHR000N.PROD.YE.PWP010.G0010V00

WHR000N.PROD.YE.PWP010.G0011V00

WHR000N.PROD.YE.PWP010.G0012V00

WHR000N.PROD.YE.PWP010.G0013V00

WHR000N.PROD.YE.PWP010.G0014V00

WHR000N.PROD.YE.PWP010.G0015V00

WHR000N.PROD.YE.PWV010.G0001V00

WHRO00N.PROD.YE.WHRSEC

CY 1997 master tapes

WHR000R.PROD.RCMSTRAB Absence History Master File

WHR000R.PROD.RCPWH010

WHR000R.PROD.RCPWK010 Check Reversal Master File

WHR000R.PROD.RCPWP010 Employee Master File

WHR000R.PROD.RCPWQ010 Audit Database Master File

WHR000R.PROD.RCPWR060 Payroll Reporting Detail File

Final tape for $1-1-98$ to $9-30-98$ (identifier is TBD) 
In addition the following source code libraries will be sent to RMIS:

\author{
WHR000N.PROD.COPYLIB \\ WHRO00N.PROD.JCLLIB \\ WHR000N.PROD.PARMLIB \\ WHRO0ON.PROD.PROCLIB \\ WHR000N.RETRO.JCLLIB \\ WHRO00N.RETRO.SRCELIB \\ WHRO00N.TEST.COPYLIB \\ WHR000N.TEST.DOCLIB \\ WHR000N.TEST.JCLLIB \\ WHR000N.TEST.LOADLIB \\ WHR000N.TEST.PARMLIB \\ WHR000N.TEST.PROCLIB \\ WHR000N.TEST.SRCELIB \\ WHRO0ON.USER.DOCLIB \\ WHRO00N.USER.JCLLIB \\ WHRO00N.USER.LOADLIB \\ WHR000N.USER.PARMLIB \\ WHRO0ON.USER.SRCELIB \\ WHR000N.YREND.JCLLIB \\ WHROOON.YREND.SRCELIB \\ HSP000N.PROD.HR9108.COPYLIB \\ HSP000N.PROD.HR9108.LOADLIB \\ HSPO0ON.PROD.HR9108.OLOADLIB \\ HSP000N.PROD.HR9108.SRCELIB \\ MSA110N.PROD.HR9108.DATALIB \\ MSA110N.PROD.HR9108.JCLLIB \\ MSA110N.PROD.HR9108.LOADLIB \\ MSA110N.PROD.HR9108.OBJLIB \\ MSA110N.PROD.HR9108.PARMLIB \\ MSA110N.PROD.HR9108.PROCLIB
}

These tapes represent year-end summary of individual payroll information for the PHMC and predecessor companies back to CY1988. The following steps will be taken to preserve this information:

- Run a final 'year end' report for the period 1-1-98 to 9-30-98, e.g. close out the data collection and processing in WHR.

- Run reports against each tape that will contain year-end summary information for each (former and current) employee in a text file format ("95 report").

- Collect these output reports into a file, 1 per calendar year and store in RMIS as sensitive data. 
Data recovery would then be a matter of gaining access to the appropriate file and printing off the selected portion of the file. At present there are no requirements for maintaining data processing and analysis capability. Current use of this data is for retrieval of the data only.

The source code files for WHR and for HRP are intermixed. These files will be written to RMIS in native file formats.

An index file to all of the above information will be prepared and also stored in RMIS. 


\section{APPENDIX N, HRP}

Human Resources Payroll

The Completed Retirement Checklist is:

1. Hardware Redeployment: runs on the Enterprise Server which is covered under a separate retirement plan.

2. Network Administration Coordination: $\mathrm{N}$

3. Production Schedule Updates: Yes, Emergency Call lists will be updated.

4. Jet Form Removal: $\mathrm{N}$

5. User Access Removal: $Y$

6. Data Retention: 3 year history kept on magnetic tape in records holding

7. Software Distribution Removal: $N$

8. Documentation Storage: Hardcopy binders only

9. Termination of License Agreements: $N$

10. Delete/Archive mailbox data: $\mathrm{N}$

11. RIDS / QA updates: updated as a result of this planning effort

12. End User De-Installation:

See WHR (appendix M) for data retention and document storage instructions. 


\title{
APPENDIX N, RIDS Process
}

\author{
Record Identification \\ And \\ Disposition Schedule \\ Process
}

The process described in this appendix was used to identify the data to be retained after the retirement of the systems described above.

The process consists of a flow chart for working through the decision process of what data to retain and for how long. There is a text description / explanation to go with the flow chart. The decisions and related information are captured on a spreadsheet RIDS template that can be obtained from LMSI Records Management. 


\section{ELECTRONIC SYSTEMS - INTERVIEW}

\section{REFERENCES (add Intranet location)}

44 United States Code (U.S.C.) 3301 - states that records include all books, papers, maps, photographs, machine readable materials or other documentary materials, regardless of physical form or characteristics.

Title 36, Code of Federal Regulation (CFR), Chapter XII, Subchapter B, Part 1228, "Disposition of Federal Records" prescribes policies for records management programs relating to records creation and maintenance, adequate documentation, and proper records disposition of federal documentary material to include all media types and formats.

Title 36, Code of Federal Regulation (CFR), Chapter XII, Part 1234, "Electronic Records Management" establishes the basic requirements related to the creation, maintenance, use, and disposition of electronic records.

\section{ELECTRONIC RECORDS MANAGEMENT TERMS}

DATA BASE - A set of data, consisting of at least one file or of a group of integrated files, usually stored in one location and made available to several users at the time for various applications.

MASTER FILES - Relatively long-lived computer files containing an organized and consistent set of complete and accurate data. Usually updated periodically. Also called main files.

HISTORY FILES - Electronic files copies from inactive master files for long-term or permanent retention.

\section{DATA FILE}

- An organized collection of related data, usually arranged into logical records that are stored together and treated as a unit by a computer.

- Related numeric, textual, or graphic information that is organized in a strictly prescribed form and format. Used in contrast to text documents that may be recorded on electronic media.

\section{DATA SET (Series Description)}

- A group of related electronic records that are organized and treated as a unit. Also used interchangeably with data file.

- A modem, which is an electronic device making possible the transmission of data to or from a computer by telephone or other communication lines.

ELECTRONIC RECORDS - Records stored in a form that only a computer can process. Also called machine-readable records or ADP records. 
BACKING UP - Making a copy of a computer file for use if the original is lost, damaged, or destroyed. Sometimes called archiving.

HISTORY FILES - Electronic files copies from inactive master files for long-term or permanent retention.

SYSTEM DOCUMENTATION - Documentation is the information needed to use computer files. It includes but is not limited to data systems specifications, file specifications, codebooks, record layouts, user guides, output specifications, and final reports (regardless of medium) relating to a master file or database. 


\section{ADMINISTRATIVE INFORMATION}

(1) SYSTEM NAME/ACRONYM

(2) BUSINESS OWNER/CONTRACTOR

(3) TECHNICAL OWNER/CONTRACTOR

(3a) SYSTEM ANALYST/CONTRACTOR

(4) PERSON(S) CONDUCTING INTERVIEW

(5) HARDWARE/SOFTWARE ENVIRONMENT

(6) PURPOSE AND USE OF THE SYSTEM Indicate the reasons for the system and it's use. Describe main subject matter, date ranges, update cycle information, and other major characteristics of the system.

\section{(7) SYSTEM DATA}

\section{DATA INPUTS AND SOURCES}

Identify and describe primary data input documents and sources, include all media. Also include names of any other systems from which this system receives data. Data may be:

- A hardcopy form such as a purchase order

- An electronic feed file, e.g., data passed into the system from an upstream process

\section{MAJOR OUTPUTS}

Identify and describe the system's major data outputs and their frequency, e.g., reports, tables, charts, graphics, prepared weekly, monthly, quarterly, yearly. Data may be:

- An electronic feed file, e.g., data passed out of the system to a downstream process

- A hard copy printout from the system

- Magnetic tapes/cartridges

INTERNAL DATA

Identify and describe the self-contained data by Data Set, Data Unit, or Data Files. For example:

- RPHO00R.PROD.TAPE.RPH - Yearly backup of alternations, cost, item. Purchase Orders, receipt and archive information. 


\section{SYSTEM DOCUMENTATION}

Identify any system specifications, file specifications, codebooks, file layouts, user guides, output specifications, and related indexes.

\section{BACKUP INFORMATION}

Identify and describe identical information that is used if the system data is lost, damaged, or destroyed.

\section{QUESTIONS - SYSTEM DATA}

(8) MEDIA

(9) LOCATION

(10) CUSTODIAN

(11) LEGAL VALUE?

- (11a) If yes, define law citation, regulatory requirement, contract clause, procedure, or Litigation Survey Number.

(12) DATA FULFILLS BUSINESS NEED ? (Operational Value, Administrative Value, Financial Value, Physical Value)

- (12a) If yes, describe usefulness or business need

\section{REPLACES HARD COPY?}

A choice must be made as to whether the electronic data replaces data contained in hardcopy form. If the data replaces hardcopy, then the electronic data becomes the 'official' copy of the data and is retained as record material.

- If yes, have you acquired Company Legal and DOE-RL approval for this replacement?

- If yes, provide a copy of the approved DOE 1324.5 "U.S. Department of Energy Request for Records Disposition Authorization."

(14) ORIGINATES DATA?

A system may take in data and manipulate it to create new data. This data "originates" within the system and does not appear elsewhere unless it is output in a report or data feed. This data could be data that you are legally 
required to keep. An example would be "Tax Withholding" which is computed based upon the salary and specified deductions of the employee.

\section{(15) IS THIS A DATA FEED FOR THIS SYSTEM?}

Data Feeds occur when systems pass data from one to another for operational purposes. In these cases, systems that receive data from other systems are not considered the 'owner' of the data. An exception can occur when data ownership is transferred when the data is transferred. A case in point can be when active data is passed from an operational system to an archival system. The data should be considered 'input' but not a 'data feed'.

- (15a) If yes, identify system feeding data.

(16) RETENTION SCHEDULE FOR RECORD MATERIAL? (N/A for Nonrecord)

(17) RETENTION PERIOD?

For Record Material, cite the retention period prescribed by the Retention Schedule.

For Nonrecord Material, identify how long data will need to be referenced.

(18) CUT-OFF/DISPOSITION INSTRUCTIONS ?

Describe what action is taken when data is no longer useful, inactive, or retention period has been reached.

(19) CONVERSION PLANNED?

For systems that are being replaced, retired, or deactivated, is the data being converted to a new system?

- (19a) If yes, name of system.

(20) RECORD MATERIAL FOR NEW SYSTEM ?

(21) NONRECORD MATERIAL FOR NEW SYSTEM?

(22) RECORD MATERIAL FOR CURRENT SYSTEM?

(23) NONRECORD MATERIAL FOR CURRENT SYSTEM ? 
NOTE: The Hanford Site remains under a full moratorium on the destruction of record material until further notice which means that no record material can be destroyed regardless of the retention period prescribed by the retention schedule. 

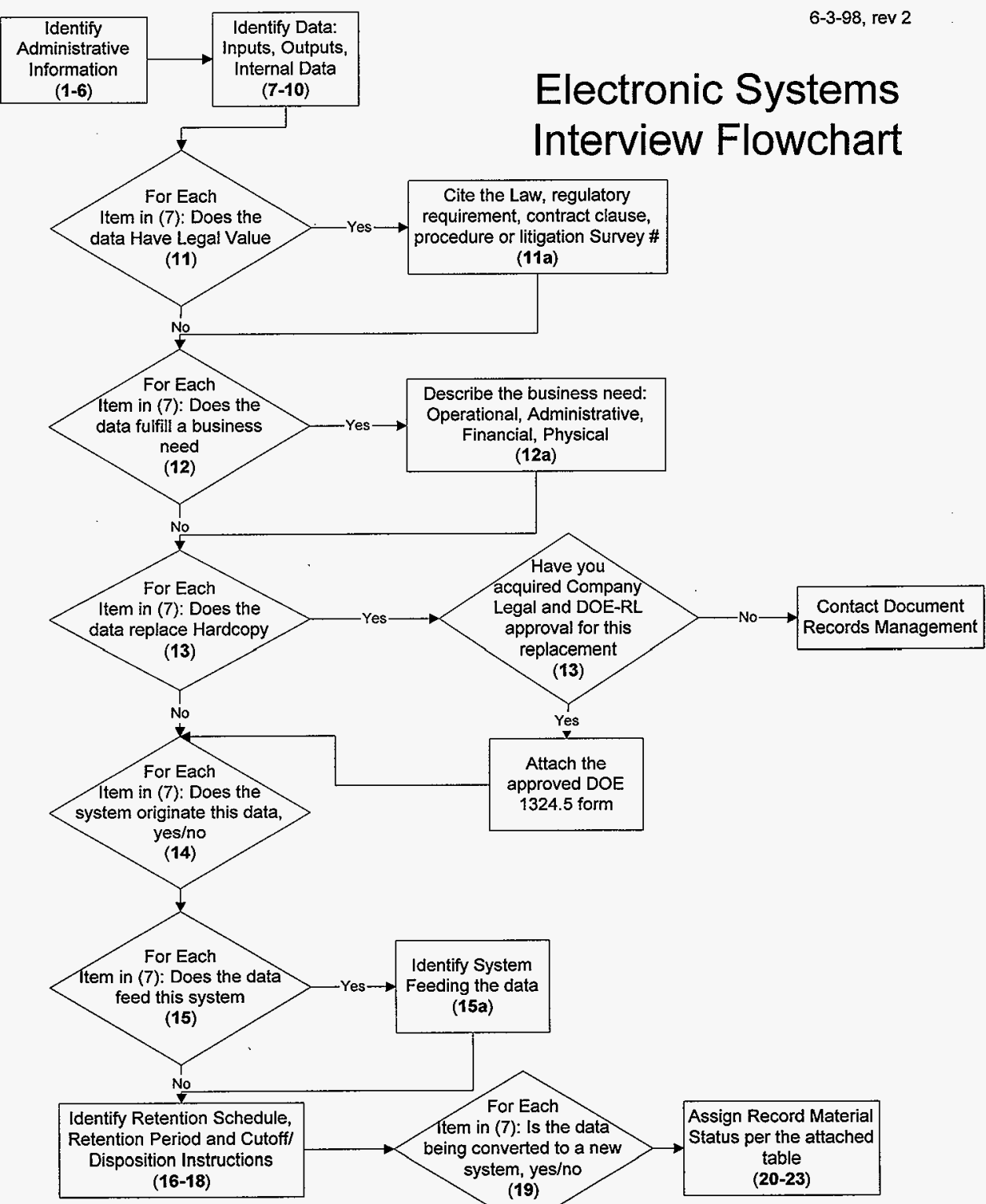
Records Material Truth Table

\begin{tabular}{|c|c|c|c|c|c|c|c|c|c|}
\hline \multicolumn{6}{|c|}{ Question } & $\begin{array}{l}\text { Record } \\
\text { Material for } \\
\text { New } \\
\text { System }\end{array}$ & \begin{tabular}{|l|} 
Non- \\
Record \\
Material for \\
New \\
System \\
\end{tabular} & \begin{tabular}{|l|} 
Record \\
Material for \\
Current \\
System
\end{tabular} & $\begin{array}{l}\text { Non- } \\
\text { Record } \\
\text { Material for } \\
\text { Current } \\
\text { System } \\
\end{array}$ \\
\hline 11 & 12 & 13 & 14 & 15 & 19 & 20 & 21 & 22 & 23 \\
\hline Yes & 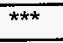 & Yes & $* * *$ & $* * \star$ & No & $\star * * *$ & $* * *$ & Yes & $* * * *$ \\
\hline Yes & $\star \star \star \star *$ & Yes & *** & $* * *$ & Yes & Yes & $* * *$ & $\star * \star *$ & *** \\
\hline Yes & $\star * * *$ & $* * *$ & Yes & $* * *$ & No & ${ }^{* * *}$ & 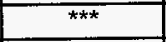 & Yes & $* * \star \star$ \\
\hline Yes & $* * *$ & $* * * *$ & Yes & $\star \star \star *$ & Yes & Yes & $\star \star \star \star$ & $* * *$ & $\star \star \star *$ \\
\hline Yes & 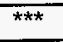 & $* * *$ & $* * * *$ & Yes & No & $\star \star \star *$ & $* \star * *$ & $\star \star \star \star \star *$ & Yes \\
\hline Yes & $\star \star \star \star *$ & $\star \star * *$ & $\star * \star *$ & Yes & Yes & $* * *$ & Yes & $\star \star \star \star$ & $\star \star \star *$ \\
\hline No & Yes & $k * \star$ & *** & $* * *$ & No & $* \star *$ & $\star \star \star \star$ & Optional & $\star \star \star *$ \\
\hline No & Yes & $* * *$ & $\star * *$ & $* * *$ & Yes & Optional & $* * *$ & $* \star *$ & $* * *$ \\
\hline No & No & $* * *$ & $* \star *$ & $* \star *$ & No & $* * *$ & $\star * * *$ & $k * \star$ & Yes \\
\hline No & No & 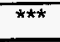 & $\star * *$ & $* \star * \pi$ & Yes & $* * *$ & Yes & $\star * * *$ & $* * *$ \\
\hline
\end{tabular}

*** $=$ either Yes or No 